\title{
Evaluation of Newly Developed Rice Lines in Lowland Ecology in Ghana
}

\author{
Esther Fobi Donkor, Remember Roger Adjei and Sober Ernest Boadu
}

\begin{abstract}
Rice is one of the major staple foods consumed in all part of the world including Ghana. The study was conducted at the research field of CSIR in Sokwai to evaluate the performance of the newly released rice varieties in lowland ecology in Ghana. The data collected were subjected to analysis of variance using Statistical Tool for Agricultural Research Version 2.0.1. The analysis of variance revealed a highly significant variation among most of the agronomic traits studied except for the panicle length, moisture content, total weight of 5 hills, the percent moisture content and the lodging index. The first five principal component (PC) accounted for $71 \%$ of the total variation with $\mathrm{PC} 1, \mathrm{PC} 2$ and $\mathrm{PC} 3$ contributing $20 \%, 17 \%$ and $13 \%$ respectively. The cluster analysis placed the accessions into five main clusters. The cophenetic correlation coefficient (CCC) was 0.42 .
\end{abstract}

Index Terms - Cluster; Correlation, Principal Component Analysis, Lowland Rice, New Varieties.

\section{INTRODUCTION}

According to the Food and Agriculture Organization (FAO) [1], the world's population is expected to reach 9.1 billion which is $34 \%$ higher than the current world population. Due to this increase the demand for food to feed the world would be more. The increase in the world population and the environment is gradually deteriorating making food security a major challenge around the globe especially in Asia and Africa. However, there is the need to improve and increase the production of rice to satisfy the high demand [2], [3].

Rice (Oryza sativa) is one of the major successful staple food in Ghana which is due to the rapid change in the lifestyle and food habit of Ghanaians in most urban settings [4]. Rice belongs to the grass family Poaceae (Gramineae) and a diploid species with $2 \mathrm{n}=24$ chromosome and is classified as a monocotyledonous plant [5].

It plays a major role in the economy and agricultural sector of Ghana. It principally accounts for about $15 \%$ of the GDP of the country. However, it is a major agricultural produce that provides employment in the rural settings. Lowlands are mostly composed of floodplains and inland valleys which occurs throughout Ghana. These lowlands have been characterized as heterogeneous in soil type morphology, vegetation and hydrology. Lowland soils therefore occur in all agro ecological zones of the world. Such agro ecological zones include the drier Savannah (Sudan, Guinea and Coastal) which covers the northern and coastal regions and

Published on December 10, 2020.

E. F. Donkor, Department of Horticulture and Crop Production, School of Agriculture and Technology, Dormaa-Ahenkro Campus, University of Energy and Natural Resources, Ghana.

(e-mail: destherfobi@yahoo.com /esther.donkor ${ }^{@}$ uenr.edu.gh) the forest regions which covers the western, central and eastern corridors of the country [6].

The current study seeks to evaluate the genetic diversity in the rice newly rice varieties released in a lowland ecology in Ghana based on their agronomic traits.

\section{MATERIALS AND METHOD}

\section{A. Experimental Procedure and Plant Materials}

Forty-five (45) rice lines, including ARICA 2 (West Africa regional check); CRI-Jasmine 85 and AgraRice were used as national and local checks respectively (Table 1). They were evaluated under rain fed and lowland irrigated condition during the 2018 major cropping season at the site of Crops Research Institute of CSIR, Ghana at Sokwai in the Atwima Nwabiagya Municipality. Lay outing was done and a $2 \times 4 \mathrm{~m}^{2}$ plot were arranged in a square block with a distance of 1 meter between blocks in an alpha-lattice design with three replications. Fourteen days-old seedlings were transplanted planted using a planting distance of $20 \times 20 \mathrm{~cm}$ with two seedlings per hill. Two border rows of local checks were used to surround the entire experiment using a distance of $40-60 \mathrm{~cm}$ in order to reduce side effects.

Fertilizer rate of 90-60-60- kg NPK/ha was applied using complete fertilizer (15-15-15) and urea (46-0-0). These were applied in split application. The required amount of phosphorous and potassium plus $1 / 3$ of the $\mathrm{N}$ requirement were applied a week after transplanting. The remaining $\mathrm{N}$ was applied in split, at 30 days after transplanting (DAT) and 45 DAT. After transplanting, the area was sprayed with baylluscide to protect the newly transplanted seedlings from golden snail. Insecticides were sprayed during the vegetative stage and at flowering to control rice bugs and other pests such as leaf hoppers and stem borers. Fungicide was also sprayed to control blight and narrow leaf spot diseases which were observed at peak tillering stage of the rice plants. After transplanting, a pre-emergent herbicide (machete) was sprayed to prevent the growth of weeds. Spot weeding by hand pulling was also done. Water level of $2-3 \mathrm{~cm}$ was maintained during the early growth of the plants and $5 \mathrm{~cm}$ during the later stages. A week before harvesting, irrigation water was controlled for ease in harvesting. Harvesting of rice lines was done manually with sickles when the crop reached $85 \%$ Physiological maturity period. Harvesting seeds were sun dried to attained $13 \%$ moisture content level.

R. R. Adjei, Department of Horticulture and Crop Production, School of Agriculture and Technology, Dormaa-Ahenkro Campus, University of Energy and Natural Resources, Ghana.

(e-mail: rogerzinadjei@gmail.com/remember.adjei@ uenr.edu.gh )

S. E. Boadu, CSIR - Crop Research Institute, Ghana.

(e-mail: sobereboadu@yahoo.com) 
Data collection was carried out using the IRRI scoring evaluation system and the African rice descriptors for rice [7].

TABLE 1: RICE LINES DESIGNATION AND STATUS.

\begin{tabular}{|c|c|c|}
\hline & Designation & Status \\
\hline 1. & ARICA 2 & Africa Rice check \\
\hline 2. & ART100-16-1-2-B-B & Africa Rice \\
\hline 3. & ART125-26-1-1-B-B & Africa Rice \\
\hline 4. & ART132-35-1-1-B-B & Africa Rice \\
\hline 5. & ART147-11-1-1-B-B & Africa Rice \\
\hline 6. & ART147-26-1-1-B-B & Africa Rice \\
\hline 7. & ART152-3-1-1-B-B & Africa Rice \\
\hline 8. & ART161-1-14-1-B-B & Africa Rice \\
\hline 9. & ART161-1-39-1-B-B & Africa Rice \\
\hline 10. & AgraRice & National Check \\
\hline 11. & ART173-10-1-1-B-B & Africa Rice \\
\hline 12. & ART192-1-16-1-B & Africa Rice \\
\hline 13. & ART174-7-1-1-B-B & Africa Rice \\
\hline 14. & ART175-13-2-1-B-B & Africa Rice \\
\hline 15. & ART174-2-1-1-B-B & Africa Rice \\
\hline 16. & Jasmine 85 & Local Check \\
\hline 17. & ART161-1-76-1-B-B & Africa Rice \\
\hline 18. & ART176-9-1-1-B-B & Africa Rice \\
\hline 19. & ART195-1-1-1-B-B & Africa Rice \\
\hline 20. & ART211-1-53-1-B-B & Africa Rice \\
\hline 21. & ART215-1-5-1-B-B & Africa Rice \\
\hline 22. & ART230-1-60-1-B-B & Africa Rice \\
\hline 23. & ART245-1-16-1-B-B & Africa Rice \\
\hline 24. & ART245-1-40-1-B-B & Africa Rice \\
\hline 25 . & ART245-1-73-1-B-B & Africa Rice \\
\hline 26. & ART246-1-8-1-B-B & Africa Rice \\
\hline 27. & ART248-1-56-1-B-B & Africa Rice \\
\hline 28. & ART248-1-69-1-B-B & Africa Rice \\
\hline 29. & ART248-1-85-1-B-B & Africa Rice \\
\hline 30. & ART248-1-93-1-B-B & Africa Rice \\
\hline 31. & ART248-1-97-1-B-B & Africa Rice \\
\hline 32. & ART249-1-6-1-B-B & Africa Rice \\
\hline 33. & ART250-1-1-1-B-B & Africa Rice \\
\hline 34. & ART250-1-20-1B-B & Africa Rice \\
\hline 35. & ART346-10-1-1-B & Africa Rice \\
\hline 36. & ART347-8-2-1-B & Africa Rice \\
\hline 37. & ART348-4-1-1-B & Africa Rice \\
\hline 38. & ART350:10-2-1-B & Africa Rice \\
\hline 39. & ART64-31-1-1-B-B & Africa Rice \\
\hline 40. & ART67-26-1-1-B-B & Africa Rice \\
\hline 41. & ART67-48-1-1-B-B & Africa Rice \\
\hline 42. & ART75-30-1-1-B-B & Africa Rice \\
\hline 43. & ART93-7-1-1-B-B & Africa Rice \\
\hline 44. & ART98-147-1-1-B-B & Africa Rice \\
\hline 45. & ART98-96-1-2-B-B & Africa Rice \\
\hline
\end{tabular}

Statistical Analysis
The data collected were subjected to Analysis of Variance (ANOVA) using the Statistical Tool for Agricultural Research Version 2.0.1.

\section{RESULTS AND DISCUSSION}

\section{A. Analysis of Variance}

From the results obtained the means, ranges, coefficient of variation $(\mathrm{CV})$ and mean squares of the 12 characters are presented in Table 2. The analysis of variance revealed highly significant $(p<0.01)$ genotypic mean squares observed among the genotypes for all agronomic traits studied except the panicle length, moisture content, total weight of 5 hills, the percent moisture content and the lodging index. The variation observed among the various rice accession be exploited for breeding and selection programmes for improved genotypes for rice production. [8], [9] and [10] also reported highly significant variation among the traits studied.

\section{B. Principal Component}

The variation among the traits were assessed using the principal component analysis for the accessions used for the study. The first five (5) principal component accounted for $71 \%$ of the total variation (Table 3 ). PC 1 revealed a total variation of $20 \%$ with an eigenvalue of 2.65 with the plant height, culm length, the number of tiller per plant and the panicle number accounting for the variation among the accession. PC2, PC3 and PC4 accounted for 17\%, 13\% and $11 \%$ respectively of the total variation among the accessions with eigenvalues of 2.22, 1.76 and 1.44 respectively. PC5 explained $9 \%$ of the entire variation with an eigenvalue of 1.22. The positive values of different traits in the PCA indicated their importance in divergence among the accessions while the negative values showed the lowest contribution to the divergence. Principal component analysis has also been in rice reported by [11], [12] and [13].

\begin{tabular}{ccccccc}
\multicolumn{6}{c}{ TABLE 2: ANALYSIS OF VARIANCE FOR THE AGRONOMIC TRAITS STUDIED } \\
\hline Traits & Mean & MSG & MSE & CV $(\%)$ & SE & Range in variation \\
\hline PH & 141.4 & $400.44^{* *}$ & 86.11 & 6.6 & 5.35 & $115.27-170.13$ \\
CL & 114.6 & $383.01^{* *}$ & 85.06 & 8 & 5.35 & $93.27-141.40$ \\
PL & 26.8 & 31.91 & 24.27 & 18.4 & 2.84 & $18.87-30.93$ \\
TNP & 11 & 4.942 & 3.361 & 16.7 & 1.06 & $8.53-12.73$ \\
PN & 10.4 & $4.829^{* *}$ & 2.607 & 15.5 & 0.93 & $7.87-13.27$ \\
PWBW (Kg) & 3.369 & $0.9585^{* *}$ & 0.3888 & 18.5 & 0.36 & $2.47-4.47$ \\
MC & 16.25 & 3.148 & 3.077 & 10.8 & 1.013 & $14.57-19.43$ \\
PWAW (Kg) & 2.944 & $0.9033^{* *}$ & 0.4007 & 21.5 & 0.37 & $2.07-4.07$ \\
1000 GW(g) & 32.38 & $20977.445^{* *}$ & 5.364 & 7.2 & 1.34 & $21.30-32.13$ \\
TWH (g) & 165.4 & 2224 & 1599 & 24.2 & 23.09 & $129.9-211.7$ \\
MC\% & 13.01 & 127.4 & 129 & 87.3 & 6.557 & $11.07-12.90$ \\
LI & 51.2 & 1179 & 1434 & 74 & 21.86 & $10.0-83.3$ \\
DM & 131.52 & $45.01^{* *}$ & 11.26 & 2.6 & 1.94 & $123.33-141.00$ \\
DF50 & 92.9 & $46.846^{* *}$ & 4.593 & 2.3 & 1.24 & $86.00-101.00$
\end{tabular}

Where $* *=$ Significant at $\mathrm{P}<0.01$ level of probability, $\mathrm{SE}=$ Standard error of the mean, $\mathrm{CV}=$ Coefficient of Variation, $\mathrm{PH}=\mathrm{Plant}$ Height, $\mathrm{CL}=\mathrm{Culm}$ Length, $\mathrm{PL}=$ Panicle Length, TNP =Tiller No/Plant, PN =Panicle Number, PWBW =Plot Weight Before Winnowing, $\mathrm{MC}=$ Moisture Content, PWAW =Plot Weight After Winnowing, TWH =Total Weight of 5 Hills, LI =Lodging Incidence, DM =Days to Maturity, DF50 =Days to 50\% Flowering, MSG = Mean Square Genotype, MSE = Mean Square Environment. 
The biplot reveals the relationship between the traits studied for the accession. The biplot which separated the accessions were based on PC 1 and PC2 (Fig. 1). The scattering of the accession in all the different quarters of the biplot suggest high degree of genetic variation among the accessions studied. More attention is paid on the traits defined in the PC1 for varietal development.

TABLE 3: PRINCIPAL COMPONENT ANALYSIS AMONG THE ACCESSIONS

\begin{tabular}{cccccc}
\hline Variables & PC1 & PC2 & PC3 & PC4 & PC5 \\
\hline PH & 0.4519 & 0.3911 & 0.0816 & 0.1173 & -0.0767 \\
CL & 0.4600 & 0.3679 & -0.0328 & 0.1726 & -0.0351 \\
PL & 0.0073 & 0.1107 & 0.4029 & -0.1824 & -0.1497 \\
TNP & -0.4073 & 0.3777 & -0.2215 & 0.1482 & 0.0477 \\
PN & -0.4325 & 0.3690 & -0.1870 & 0.1957 & 0.0303 \\
PWBW (Kg) & 0.1492 & -0.2544 & -0.1008 & 0.5289 & -0.3580 \\
MC & 0.0684 & -0.1401 & -0.1120 & -0.2729 & -0.6583 \\
PWAW (Kg) & -0.0132 & -0.1521 & -0.1717 & 0.6217 & -0.0416 \\
1000wt (g) & 0.2863 & -0.3039 & -0.1068 & 0.0874 & 0.3197 \\
TWH (g) & 0.0050 & 0.3331 & -0.0506 & 0.0020 & -0.4503 \\
MC\% & 0.2378 & 0.2662 & 0.1446 & 0.0363 & 0.3029 \\
LI & -0.0804 & 0.0961 & 0.6115 & 0.2651 & -0.0500 \\
DM & -0.2431 & -0.1726 & 0.5338 & 0.2072 & -0.0696 \\
\% Variance & 20 & 17 & 13 & 11 & 9 \\
Cumulative \% & 20 & 37 & 51 & 62 & 71 \\
Variance & & & & & \\
EigenValues & 2.65 & 2.22 & 1.76 & 1.44 & 1.22 \\
\hline
\end{tabular}

$\mathrm{PH}=$ Plant Height, $\mathrm{CL}=$ Culm Length, $\mathrm{PL}=$ Panicle Length, TNP =Tiller No/Plant, $\mathrm{PN}=$ Panicle Number, $\mathrm{PWBW}=$ Plot Weight Before Winnowing, $\mathrm{MC}=$ Moisture Content, PWAW =Plot Weight After Winnowing, TWH $=$ Total Weight of 5 Hills, LI =Lodging Incidence, DM =Days to Maturity, DF50 $=$ Days to $50 \%$ Flowering.

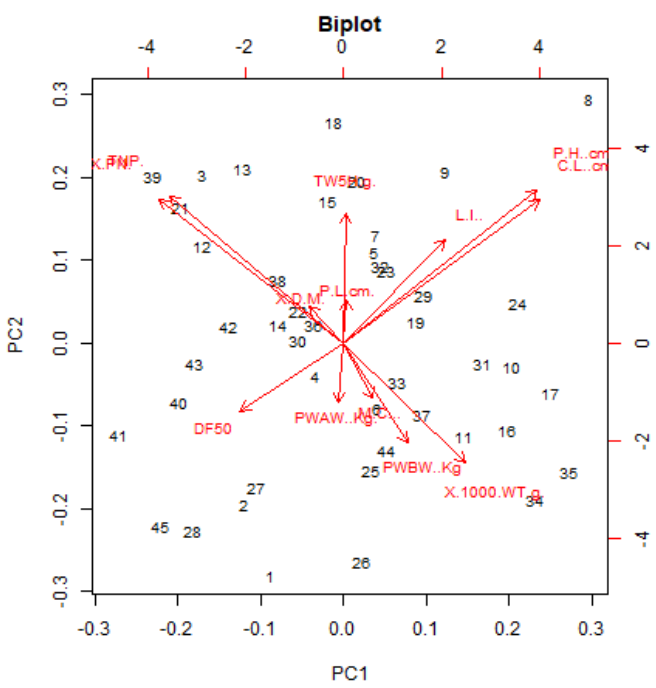

Fig. 1. Biplot of the morphological traits of the forty-five accessions.

\section{Clustering of accessions based on morphological traits}

The cophenetic correlation coefficient (CCC) was 0.42 . The resultant dendogram grouped the forty-five accessions into five clusters (Fig. 2). Table 4 shows the clusters, number of accessions and the accessions in each cluster. The largest cluster was III with 19 accessions followed by cluster I with
9 accessions while cluster $\mathrm{V}$ was the smallest with 5 members. The clustering pattern of the accessions suggests that the accessions from the same location can be grouped into different clusters. This pattern shows that the geographic distribution of the accession was not a basis for the genetic diversity of the accessions. Similar observation was reported by [11], [14]. The cluster means of the traits studied are presented in Table 5. Cluster I showed highest mean value for moisture content (16.64) and the shortest days to maturity (129.22). Cluster II exhibited the highest mean value for number of tillers per plant (12.54), panicle number (11.86), plot weight after winnowing (3.35), total weight of 5 hills (172.2) and lodging incidence (66.83). Cluster III are defined as having the highest plant height (148.62), culm length (121.37) and shortest period for days to $50 \%$ flowering (90.4). Cluster IV was also distinguished with highest panicle length. (29.29). Cluster V exhibited highest mean value for the plot weight before winnowing (4.0) and 1000 grain weight (35.79). The result implies that the accessions in cluster $\mathrm{V}$ are high yielding while accessions in cluster II also possess important traits that could be considered during improvement and development of new cultivars. However, the accession within a particular cluster are genetically related nevertheless they might have been separated morphologically as a result of environmental influence over a particular period of time.

TABLE 4: Clustering OF THE ACCESSIONS BASED ON MORPHOLOGICAL TRAITS

\begin{tabular}{|c|c|c|}
\hline Cluster & $\begin{array}{l}\text { Number } \\
\text { of } \\
\text { accessions }\end{array}$ & Accessions \\
\hline I & 9 & $\begin{array}{l}\text { AgraRice, ARICA 2, ART246-1-8-1-B- } \\
\text { B, ART248-1-56-1-B-B, ART248-1-69-1- } \\
\text { B-B, ART248-1-85-1-B-B, ART75-30-1- } \\
\text { 1-B-B, ART98-147-1-1-B-B, Jasmine85. } \\
\text { ART100-16-1-2-B-B, ART125-26-1-1- }\end{array}$ \\
\hline II & 6 & $\begin{array}{c}\text { B-B, ART175-13-2-1-B-B, ART230-1-60- } \\
\text { 1-B-B, ART245-1-40-1-B-B, ART248-1- } \\
\text { 93-1-B-B }\end{array}$ \\
\hline III & 19 & $\begin{array}{c}\text { ART132-35-1-1-B-B, ART147-11-1-1- } \\
\text { B-B, ART147-26-1-1-B-B, ART152-3-1- } \\
\text { 1-B-B, ART161-1-14-1-B-B, ART161-1- } \\
\text { 39-1-B-B, ART161-1-76-1-B-B, ART174- } \\
\text { 2-1-1-B-B, ART174-7-1-1-B-B, ART192- } \\
\text { 1-6-1-B-B, ART195-1-1-1-B-B, ART211- } \\
\text { 1-53-1-B-B, ART215-1-5-1-B-B, } \\
\text { ART245-1-16-1-B-B, ART245-1-73-1-B- } \\
\text { B, ART248-1-97-1-B-B, ART249-1-6-1- } \\
\text { B-B, ART250-1-1-1-B-B, ART250-1-20- } \\
\text { 1B-B }\end{array}$ \\
\hline IV & 6 & $\begin{array}{l}\text { ART173-10-1-1-B-B, ART348-4-1-1- } \\
\text { B, ART64-31-1-1-B-B, ART67-26-1-1-B- } \\
\text { B, ART67-48-1-1-B-B, ART93-7-1-1-B-B }\end{array}$ \\
\hline V & 5 & $\begin{array}{c}\text { ART176-9-1-1-B-B, ART346-10-1-1- } \\
\text { B, ART347-8-2-1-B, ART350:10-2-1-B, } \\
\text { ART98-96-1-2-B-B }\end{array}$ \\
\hline
\end{tabular}

TABLE 5: CLUSTERS MEAN PERFORMANCE FOR CHARACTERS IN RICE

\begin{tabular}{ccccccccccccccc}
\hline Cluster & PH & CL & PL & TNP & XPN & PWBW & MC & PWAW & 1000 wt & TWH & LI & DM & DF50 \\
\hline I & 124.53 & 98.78 & 25.75 & 10.73 & 10.12 & 3.53 & 16.64 & 3.04 & 32.27 & 163.46 & 32.98 & 129.22 & 94.7 \\
II & 142.29 & 117.73 & 24.56 & 12.54 & 11.86 & 3.55 & 16.07 & 3.35 & 32.47 & 172.2 & 66.83 & 130.33 & 91.66 \\
III & 148.62 & 121.37 & 27.25 & 10.79 & 10.21 & 3.23 & 16.45 & 2.78 & 31.92 & 170.55 & 52.88 & 130.95 & 90.4 & 135 \\
IV & 138.24 & 108.95 & 29.29 & 11.82 & 11.27 & 2.85 & 15.97 & 2.81 & 31.08 & 157.1 & 52.4 & 136.33 & 97.11 \\
V & 147 & 120.35 & 26.65 & 9.48 & 8.81 & 4 & 15.36 & 3.07 & 35.79 & 151.36 & 56.62 & 133.47 & 95.53 \\
\hline
\end{tabular}

PH =Plant Height, $\mathrm{CL}=$ Culm Length, $\mathrm{PL}=$ Panicle Length, TNP =Tiller No/Plant, PN =Panicle Number, PWBW =Plot Weight Before Winnowing, MC $=$ Moisture Content, PWAW =Plot Weight After Winnowing, TWH =Total Weight of 5 Hills, LI =Lodging Incidence, DM =Days to Maturity, DF50 =Days to $50 \%$ Flowering. 


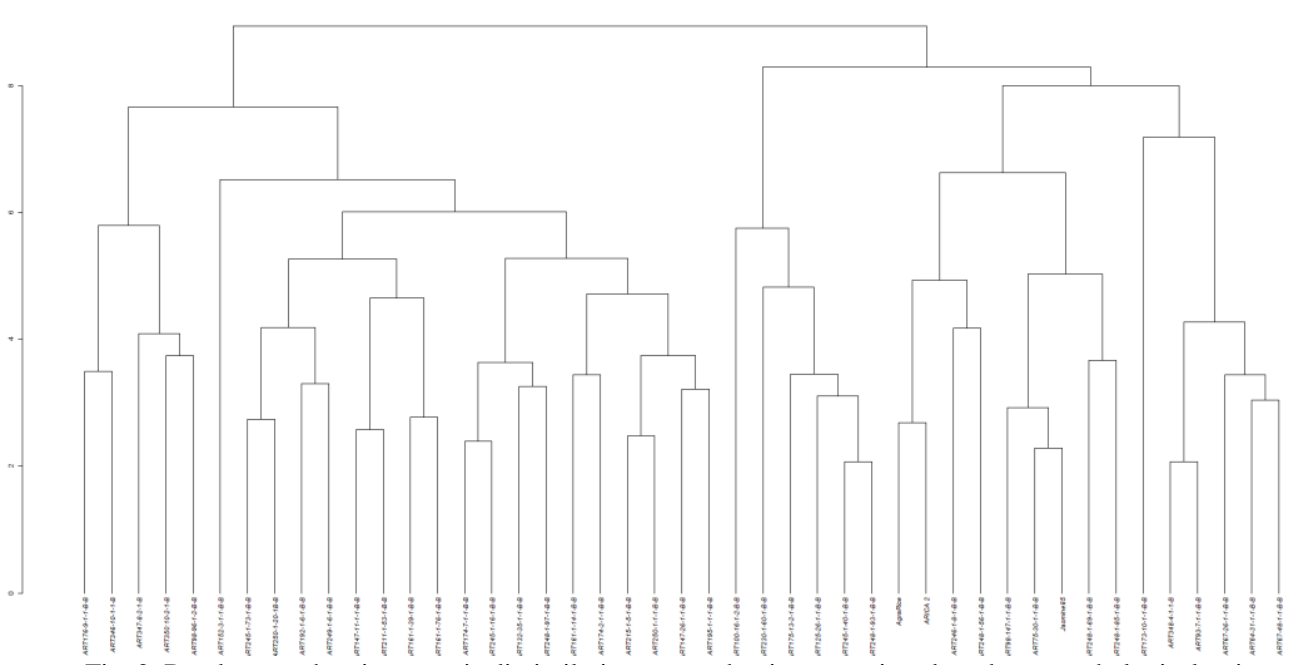

Fig. 2. Dendogram showing genetic dissimilarity among the rice accessions based on morphological traits

\section{Correlation Among the Agronomic Traits}

The correlation among the agronomic traits was accessed using the Pearson correlation to determine the relationship between the agronomic traits studied. Highly significant and positive correlation was recorded between plant height and culm length $(r=0.9595)$, between the panicle number and tiller number/plant $(\mathrm{r}=0.936)$, plot weight after winnowing and plot weight before winnowing $(r=0.9941)$ and also between the days to $50 \%$ flowering and the days to maturity $(\mathrm{r}=0.584)$. Positive and significant correlation was observed between lodging incidence and plant height $(r=0.3574)$, culm length $(r=0.3378)$. Negative and high significant correlation was observed between 1000 grain weight and panicle number $(\mathrm{r}=-0.398)$, number of tillers per plant $(\mathrm{r}=-$ $0.3394)$. Also, days to $50 \%$ flowering and culm length $(\mathrm{r}=-$
0.364) recorded negative and significant association. Plant height and panicle length was positively associated (Table 6). Similar observation was reported in the work of [15]. However, the agronomic traits that showed a positive and significant association in the study can be improved concurrently for breeding purposes whereas traits with negative association can be improved upon separately. The results imply that an increase in one of the positive correlated traits would result in increase in the associated traits and a negative correlation indicates that an increase in the correlated trait would result in a decrease in the other trait. For example, an increase the plant height will cause an increase in the culm length whereas an increase in the 1000 weight will cause a decrease in the panicle number.

TABLE 6: CORRELATION AMONG THE AGRONOMIC TRAITS

\begin{tabular}{|c|c|c|c|c|c|c|c|c|c|c|c|c|}
\hline & $\mathrm{PH}$ & CL & PL & TNP & PN & PWBW & $\mathrm{MC}$ & PWAW & $1000 \mathrm{wt}$ & TWH & LI & DM \\
\hline $\mathrm{PH}$ & - & & & & & & & & & & & \\
\hline $\mathrm{CL}$ & $0.9595 * * *$ & - & & & & & & & & & & \\
\hline PL & 0.2183 & -0.0654 & - & & & & & & & & & \\
\hline PN & -0.1707 & -0.1676 & -0.0241 & $0.936 * * *$ & - & & & & & & & \\
\hline PWBW & 0.0253 & 0.0716 & -0.1584 & -0.2281 & -0.1845 & - & & & & & & \\
\hline MC & -0.0106 & -0.0469 & 0.1251 & -0.1503 & -0.1728 & 0.1155 & & & & & & \\
\hline PWAW & 0.0487 & 0.0983 & -0.1679 & -0.214 & -0.174 & $0.9941 * * *$ & 0.0833 & - & & & & \\
\hline $1000 \mathrm{wt}$ & 0.0668 & 0.0953 & -0.0932 & $-0.3394^{*}$ & $-0.398 * *$ & 0.2471 & -0.0488 & 0.2602 & - & & & \\
\hline TWH & 0.1896 & 0.2102 & -0.0566 & 0.1603 & 0.192 & 0.0858 & 0.039 & 0.0925 & -0.2833 & - & & \\
\hline LI & $0.3574 *$ & $0.3378 *$ & 0.096 & -0.1071 & -0.0617 & -0.0799 & -0.2048 & -0.0742 & 0.0283 & 0.1134 & - & \\
\hline $\mathrm{DM}$ & 0.0249 & -0.0303 & 0.1933 & 0.0195 & 0.0554 & -0.0477 & -0.1241 & -0.0381 & -0.1523 & 0.0225 & -0.0439 & - \\
\hline DF50 & $-0.3253 *$ & $-0.364 * *$ & 0.1089 & -0.0588 & 0.0166 & 0.1221 & -0.1442 & 0.0994 & -0.149 & -0.0413 & -0.0978 & $0.584 * * *$ \\
\hline
\end{tabular}

Where $^{* * *}=$ significant at $0.001, * *=$ significant at 0.01 , * significant at $0.05, \mathrm{PH}=\mathrm{Plant}$ Height, CL $=$ Culm Length, PL - Panicle Length, TNP $=$ Tiller No/Plant, PN =Panicle Number, PWBW =Plot Weight Before Winnowing, MC =Moisture Content, PWAW =Plot Weight After Winnowing, TWH =Total Weight of 5 Hills, LI =Lodging Incidence, DM =Days to Maturity, DF50 =Days to $50 \%$ Flowering.

\section{CONCLUSION}

The study revealed significant variability among the germplasm evaluated giving room for selecting parental lines for the development of rice varieties adopted to lowlands in Ghana.

\section{ACKNOWLEDGEMENT}

The authors are grateful to CSRI-CRI (Ghana) for supplying the germplasm for the evaluation.

\section{REFERENCES}

[1] FAO (2009) Food and Agriculture Organization.

[2] K. A. Sanni, I. Fawole, S. A. Ogunbayo, D. D. Tia, E. A. Somado, K Futakuchi, M. Sié, F. E. Nwilene, and R. G. Guei, "Multivariate analysis of diversity of landrace rice germplasm," Crop Sci. vol. 52, no. 2, pp. 494-504, March 2012.

[3] M. M. Miah, S. M. Ali, and M. I. Hossain, "Assessment of risk factors that affecting agriculture productions and identifying adaptation options for increased productions and improved livelihoods of the farming community in the vulnerable area of droughts in Bangladesh," OJER. vol. 1, no. 4 pp. 1, Dec. 2013. 
[4] V. Balasubramanian, M. Sie, R. J. Hijmans, and K. Otsuka, "Increasing rice production in sub-Saharan Africa: challenges and opportunities" Adv. Agron. vol. 94, pp. 55-133, Jan 2007.

[5] N. R. Rangare, A. Krupakar, K. Ravichandra, A. K. Shukla, and A. K. Mishra, "Estimation of characters' association and direct and indirect effects of yield contributing traits on grain yield in exotic and Indian rice (Oryza sativa L.) germplasm," Int. J. Agric. Sci. vol. 2, no. 1, pp. 54-61, 2012.

[6] M. M. Buri, R. N. Issaka, T. Wakatsuki, and N. Kawano, "Improving the productivity of lowland soils for rice cultivation in Ghana: The role of the Sawah system," J. Soil Sci. Environ. vol. 31, no. pp. 356-65. March 2012.

[7] IRRI (2017) International Rice Research Institute. IRRI World Rice Statistics http://ricestat.irri.org:8080/wrsv3/entrypoint.htm.

[8] M. A. Zahid, M. Akhter, M. Sabar, Z. Manzoor, and T. Awan, "Correlation and path analysis studies of yield and economic traits in Basmati rice (Oryza sativa L.)," Asian J. Plant Sci., vol. 5, no. 4, pp. 643-645, 2006

[9] F. E. Yong-xiang. "Correlation and cluster analysis for yield properties of early-japonica rice in cold area," J. Anhui Agric. Univ., vol. 23, no. 49, pp. $150-186,2008$

[10] M. M. Rahman, A. Hussain, M. A. Syed, A. Ansari, and M. A. Mahmud, "Comparison among clustering in multivariate analysis of rice using morphological traits, physiological traits and simple sequence repeat markers," AEJAES, vol. 1, pp. 876-882, 2011.

[11] A. Anandan, R. Eswaran, and M. Prakash, "Diversity in rice genotypes under salt affected soil based on multivariate analysis," JTAS, vol. 34, no. 1, pp. 33-40, Feb 2011.

[12] M. A. Latif, M. M. Rahman, M. S. Kabir, M. A. Ali, M. T. Islam, and M. Y. Rafii, "Genetic diversity analyzed by quantitative traits among rice (Oryza sativa L.) genotypes resistant to blast disease," Afr. J. Microbiol. Res., vol. 5, no. 25, pp. 4383-4391, Nov 2011.

[13] S. Chakma, M. M. Rahman, P. Islam, M. A Awal, U. K. Roy, and M. R. Haq, "Arsenic in rice and rice straw," $B V J$, vol. 16, no. 1, pp. 1-6, Sep 2012.

[14] G. S. Yadav, R. Lal, R. S. Meena, S. Babu, A. Das, S. N. Bhowmik, M. Datta, J. Layak, and P. Saha, "Conservation tillage and nutrient management effects on productivity and soil carbon sequestration under double cropping of rice in north eastern region of India," Ecol. Indic., vol. 1, no. 105, pp. 303-315, Oct 2019.

[15] K. M. Iftekharuddaula, K. Akter, M. S. Hassan, K. Fatema, and A. Badshah, "Genetic divergence, character association and selection criteria in irrigated rice," J. Bio. Sci.; vol. 2, no. 4, pp. 243-246, 2002. 